\title{
Relative Leader-Member Exchange, Negative Affectivity and Social Identification: A Moderated-Mediation Examination
}

\begin{abstract}
We argue that leader-member exchange (LMX) standing relative to the LMX relationships of other coworkers (RLMX) in workgroups may influence employees’ job performance. Based on social comparison and social identity theories, we develop a moderated-mediation model of the psychological processes linking RLMX and job performance, and test it on a sample of 252 employees and 42 managers working in two large banks. Results of hierarchical regression analyses provide support for the model. We found that RLMX was positively related to social identification after controlling for perceptions of LMX; and also that social identification mediated the relationship between RLMX and job performance. We found further that negative affectivity moderated the relationship between RLMX and social identification which, in turn, also mediated the interactive effect on job performance.
\end{abstract}

Key words: Relative leader-member exchange (RLMX); negative affectivity (NA); social identification 


\section{Relative Leader-Member Exchange, Negative Affectivity and Social Identification:}

\section{A Moderated-Mediation Examination}

Over the last three decades, considerable research has been undertaken to examine the importance of leader-member exchange (LMX) in the workplace (see Schyns \& Day, 2010, for a review). LMX theory focuses on differentiated interpersonal exchange relationships that leaders develop and maintain with subordinates using different leadership styles within workgroups (Dansereau, Graen, \& Haga, 1975). Although Gerstner and Day (1997) demonstrated that LMX relationships have implications for employees’ work attitudes and behaviors, LMX research to date has tended to view subordinates' LMX relationships with their leaders in isolation of the LMX relationships of other coworkers in a workgroup (Kramer, 1995; Sias \& Jablin, 1995; Sparrowe \& Liden, 1997, 2005). In this respect, a group of LMX researchers (see Henderson, Wayne, Shore, Bommer, \& Tetrick, 2008; Liden \& Antonakis, 2009; Sherony \& Green, 2002; Sparrowe \& Liden, 1997, 2005; Tse, Dasborough, \& Ashkanasy, 2008; Vidyarthi, Liden, Anand, Erdogan, \& Ghosh, 2010) have recently offered the view that interpersonal exchange relationships between leaders, subordinates, and coworkers are interconnected and embedded within a larger social network in organizations. This suggests that these exchange relationships are interdependent and can influence each other. In particular, the differential quality of LMX relationships creates a psychological boundary for interpersonal comparison that may lead each employee to be aware of her or his relative standing in a workgroup. Thus, an employees' relative standing of her or his LMX relationship (RLMX; defined as an employee's LMX quality relative to the average LMX quality of others within a workgroup) may also influence her or his work attitudes and behaviors in workgroups (see Henderson et al., 2008; Hu \& Liden, 2009; Liden \& Antonakis, 2009; Vidyarthi et al., 2010). 
According to LMX theory (see Dienesch \& Liden, 1986; Graen \& Uhl-Bien, 1995), leaders tend to develop high-quality relationships with only a few subordinates within a workgroup and these relationships serve as channels for leaders to distribute organizational resources, job-related benefits, and psychological support to subordinates. Hence, relative to other group members in a workgroup, members in higher quality LMX relationships are likely to be more advantageously treated. Employees’ LMX relationship quality therefore is likely to derive from their comparative positions in the workgroup (as compared to other coworkers' LMX relationships). Consequently, the differences between an employee’s LMX relationship and others’ LMX relationships may influence the employee’s evaluation of her or his LMX relationship (Hu \& Liden, 2008; Vidyarthi et al., 2010). Although the theoretical and practical bases of LMX differentiation have been made explicit, research examining the effect of RLMX on employees’ work attitudes and behaviors — and the underlying psychological processes involved-has only recently begun to attract attention (e.g., Henderson et al., 2008; Hu \& Liden, 2009; Vidyarthi et al., 2010).

By integrating social comparison theory (SCT: Festinger, 1954; Greenberg, AshtonJames, \& Ashkanasy, 2007) and social identity theory (SIT: Tajfel, 1972), we explore the effect of RLMX by testing a moderated-mediation model, the purpose of which is to explain the psychological process of how RLMX is related to employees’ job performance. Specifically, we propose two mechanisms by which RLMX might exert impact on performance outcomes. First, we theorize that social identification (the extent that individuals define themselves based on collective values and group characteristics; see Brewer \& Gardner, 1986) will mediate the relationship between RLMX and job performance after controlling for perceptions of LMX. Second, we posit that negative affectivity (NA; a dispositional tendency to experience negative 
emotions, see Watson \& Clark, 1984) will attenuate the relationship between RLMX and social identification. We argue further that social identification will also mediate the interactive effect between RLMX and employees’ NA on job performance.

Insert Figure 1 here

Figure 1 depicts our proposed model. Specifically, we aim to advance the new area of RLMX in LMX literature in three ways.

First, we examine the effect of RLMX on social identification. This extends current LMX research by explicating how social comparison processes occur in a set of differentiated relationships between leaders and followers in workgroups (Henderson et al., 2008; Henderson, Liden, Glibkowski, \& Chaudhry, 2009; Hu \& Liden, 2009; Vidyarthi et al., 2010). We argue in particular that, by exploring employees’ relative LMX standing as compared with others’ LMX relationships in workgroups, we address a new and critically important issue about the implication of the social context of LMX differentiation. This is because social comparisons are likely to provide a new perspective on whether RLMX is associated with employees' identity which, in turn, serves as a basis for their cognitive, affective and motivational processes.

Second, our research is in response to the call by Henderson et al. (2008) and Vidyarthi et al. (2010) to identify intervening processes that might explain relationships between RLMX and performance outcomes. Drawing on SIT and SCT, therefore, we propose that social identification mediates the relationship between RLMX and job performance. In particular, we posit that social identification has the potential to increase our understanding of how relative LMX standing is related to the way employees perceive and envision themselves in a workgroup that, in turn, may also be associated with their behavioral reactions. 
Third, we explore the moderating role of an individual difference variable, employee negative affectivity (NA), attempting to understand how LMX relationships is associated with social identity processes in workgroups. This is consistent with recent research (e.g., see Hochwarter \& Byrne, 2005; Kamdar \& Van Dyne, 2007) that has begun to explain why employees with different personality characteristics respond differentially to perceptions of their LMX relationships in workgroups. The past research, however, has not yet explored affectivebased personality variables such as NA as a moderating effect in LMX research (Bauer \& Green, 1996; Hui, Law, \& Chen, 1999). To examine this issue further, we elucidate why and when RLMX may influence the social identification of employees and, in turn, their subsequent job performance.

\section{Theoretical Background and Hypothesis Development}

\section{RLMX: Conceptualization and Empirical Evidence}

The concept of relative LMX (RLMX) was originally developed by Graen, Liden, and Hoel (1982) and is predicated on the nexus of LMX and social exchange. As such, RLMX differs from LMX in that RLMX assesses members’ relative standings in terms of their exchange relationships with the leader, whereas LMX measures the quality of relationships between leaders and their members (Henderson et al., 2008; Hu \& Liden, 2009; Vidyarthi et al., 2010). Moreover, RLMX is distinct from a newly proposed construct called LMX social comparison (LMXSC), such that the former reflects the degree to which an individual's LMX differs from the average LMX of other coworkers in a workgroup and the latter refers to individuals' subjective comparison evaluation and is obtained directly from focal employees (see Vidyarthi et al., 2010). In terms of empirical findings, recent research (e.g. Henderson et al., 2008; Hu \& Liden, 2009) has shown that RLMX is associated with important work outcomes beyond the effects of LMX. 
For example, using Graen et al.’s (1982) operationalization of RLMX as mean workgroup LMX minus each group member's individual LMX score, Henderson et al. (2008) revealed that RLMX is positively associated with psychological contract fulfillment, controlling for individuals’ perceptions of LMX. In another field study based on the same operationalization of RLMX and also controlling for the effect of LMX, Hu and Liden (2009) reported that RLMX is positively related to job satisfaction and job performance. More recently, Vidyarthi et al. (2010) found that LMXSC acts as a full mediator of the relationship between RLMX and OCBs but LMXSC only partially mediates the relationship between RLMX and job performance after controlling for the effect of LMX. These findings demonstrate that RLMX is a unique construct that is conceptually related to but different from LMX and LMXSC, respectively. We therefore expect that RLMX can explain meaningful variance in employees' work attitudes and behaviors above and beyond the individuals’ perceptions of LMXSC and LMX.

\section{Social Comparison and Social Identity Theories}

In developing the hypothesized relationships in our model, we utilize two theories:

(1) social comparison theory (Festinger, 1954; see Greenberg et al., 2007, for a review) and

(2) social identity theory (Tajfel, 1978; Tajfel \& Turner, 1986).

Social comparison theory (SCT) holds that individuals tend to self-evaluate and so learn about themselves by comparing with others in terms of attributes, abilities, and performance. Festinger (1954) postulated that social comparison processes occur when individuals lack an objective means to understand their own state in a social context. Thus, working in a group provides individuals with opportunities for social comparison because their coworkers in the same workgroup have many common attributes (e.g., reporting to the same supervisor, working in similar positions and possessing similar qualifications and experiences), and they are required 
to interact with each other to complete assigned tasks (Stapel \& Koomen, 2005). Research has also demonstrated that self-evaluation derived from social comparison serves as a foundation for cognitive, emotional, and motivational processes that can predict individuals' work attitudes and behaviors (see Buunk \& Gibbons, 2007; Greenberg et al., 2007).

Social identity theory (SIT) postulates that individuals are motivated to see themselves positively; we extend this motivation to include the individual's group memberships or what Tajfel (1978) refers to as social identities (see also Tajfel \& Turner, 1986). According to Tajfel and his associates, a person's self-concept is comprised of a personal identity (i.e., idiosyncratic characteristics such as individual attributes, abilities and past experience) and a social identity (i.e., salient group classifications and characteristics such as group attributes, processes and composition). Hogg and Terry (2000) argue that both personal and social identities are important in organizational settings because they influence individuals’ self-concept in a workgroup.

SCT and SIT share a key tenet emphasizing that individuals are driven by a desire for self-evaluation and a motivation to develop a clear self-concept (Festinger, 1954; Tajfel, 1978). This is because both theories imply that individuals are constantly exposed to various situations of self-evaluation in order to sustain their self-concept in a social context, which, in turn, influences their work attitudes and behaviors (Buunk \& Gibbons, 2007). In the context of the employees' social exchange relationships with their leaders, the above theories suggest that employees are aware of the quality of coworkers’ LMX relationships (e.g., Duchon, Green, \& Taber, 1986; Graen \& Cashman, 1975), and therefore more recent research has used a direct measure of individuals' perceptions of their LMX relationships versus others’ LMX relationships in the workgroup (LMXSC: Vidyarthi et al., 2010). Based on SCT and SIT and these recent studies, we argue that employees do form judgments about their LMX relationship relative to 
other LMX relationships that coworkers of the workgroup develop and maintain with the leader, even though RLMX is not a perceptual measure. An employee’s RLMX (either higher or lower than the average LMX of others in the workgroup) may affect how s/he perceives and envisions her/himself in the workgroup.

\section{RLMX and Social Identification}

Consistent with Henderson et al. (2008) and Vidyarthi et al. (2010), we argue that employees are aware of the quality of their LMX relationships and also form judgments of their relative LMX standing in the workgroup. This should apply even though RLMX refers to the actual degree to which an individual's LMX differs from the average leader-subordinate LMX in the workgroup. This also suggests that RLMX can be regarded as reflective of the actual position of each employee in a set of differentiated LMX relationships within a workgroup. High and low RLMX thus represents objective information that provides employees with a point of reference to understand their position relative to other coworkers’ LMX standings (Vidyarthi et al., 2010). Thus relative LMX standing helps to explain how employees perceive and define themselves in the workgroup. This is because their high or low RLMX is related to their self-concept (see Buunk \& Gibbons, 2007). We therefore contend that employees may experience feelings of superiority and respect if their LMX position is relatively higher than the LMX standing of other coworkers; and their access to benefits and resources from their leaders is also greater than the access of others in the workgroup (Henderson et al., 2008; Vidyarthi et al., 2010).

In line with this reasoning, we argue further that, if a member's RLMX is high, s/he can be expected to have a positive self-concept, and the employee's collective schemas may be activated to increase her or his identification with other coworkers (Baldwin, 1992; Shah, 2003). Thus, because their core self-representation may act to motivate their collectivistic attitudes and 
behaviors in the workgroup, members with high RLMX can be expected to be interested in collective interests and group values.

On the other hand, members with low RLMX may be expected to experience a negative self-concept and their individual schemas may be activated to decrease their identification with other coworkers (Baldwin, 1992; Shah, 2003). Thus, low RLMX members may focus on selfinterest and personal values as their core self-representation to facilitate individualistic attitudes and behaviors. This line of reasoning is also supported by interpersonal comparison research (Gardner, Gabriel, \& Hochschild, 2002) which demonstrates that, when individuals are in positive relationships, their collective selves often include overlapping connections with others. This occurs because each employee's self-definition has been expanded to incorporate those dyadic relationships as a part of their core self-representations in the workgroup. On the other hand, when employees are in negative relationships, their independent selves exclude overlapping connections with others. This occurs because each employee's self-definition has failed to be integrated with those dyadic relationships as part of their core self-representation in the workgroup.

Building on the foregoing discussion and empirical evidence, we suggest RLMX standing is likely to be related to employees’ levels of identification with their workgroup beyond LMX (i.e., their perceptions of the LMX quality). Recent LMX research (e.g., Henderson et al., 2008; Hu \& Liden, 2009) also suggests that it is important to control for the direct effect of LMX in order to understand the effect of RLMX on work attitudes and behaviors. Thus:

Hypothesis 1: RLMX is positively related to social identification (after controlling for individual perceptions of LMX quality). 


\section{Social Identification and Job Performance}

Chiaburu and Harrison (2008) noted that workgroup members’ outcomes are largely evaluated as the extent to which members' work performance exceeds their prescribed job demands and expectations at work. In this study, we include job performance as an outcome variable. Specifically, we measure job performance in terms of work requirements outlined in employees’ job descriptions (Williams \& Anderson, 1991), which refer to the quality and quantity of work that can be expected from employees.

Social identification is defined by Tajfel (1978) as the "cognition of membership of a group and the value and emotional significance attached to this membership” (p. 63). Brewer and Gardner (1986) note further that social identification occurs when individuals share beliefs with their group and define their self-concept based on the group's values and collective interests. When individuals identify with a group, they are more likely to base their self-concept at least in part on their belonging to the group and to perceive and experience group successes and failures as their own successes and failures (Ashforth \& Mael, 1989; Mael \& Ashforth, 1992). This notion implies that social identification promotes a sense of oneness among members in a workgroup and motivates individuals to think and to behave in prototypical ways in order to enhance their self-concept as group members (see also Hogg \& Terry, 2000).

In particular, social identification has the propensity to increase job performance by enabling individuals to evaluate how their own work can contribute to overall group success (Hogg \& Terry, 2000). In this respect, Van Knippenberg (2000) demonstrated that, once individuals align with the values of their workgroup, they focus on collective interests and purposes, and view their individual effort and work roles as an important contribution to a larger collective effort. This, in turn, enhances the importance of performance because both quality and 
quantity of members' jobs are perceived to be related to overall group effectiveness. Hogg and Abrams (1988) argue further that the effect of social identification on job performance can be explained in terms of the cognitive and affective identification with groups that increases individuals’ self-concept and self-efficacy (Turner, Hogg, Oakes, Reicher, \& Wetherell, 1987). The positive self-concept and increased sense of self-efficacy should then motivate individuals to perform their assigned duties better. Stamper and Masterson (2002) also found that individuals who see themselves as group or organizational insiders are more willing to accept their role responsibilities and to perform them more effectively. This is because they find the group's values meaningful and their membership valuable and rewarding. Based upon the above discussion, we next propose:

Hypothesis 2: Social identification is positively related to job performance.

\section{The Mediating Role of Social Identification}

Underpinned by SIT, we argue that social identification (driven by social comparison processes) might explain the relationship between RLMX and job performance. SIT theorists (Tajfel \& Turner, 1986) propose that social identification reflects group members’ perceptions of self-concept, and thus individuals are going to be motivated to enhance their positive self-concept by defining themselves as enthusiastic group members, whose obligations align with the interests of a social group. This suggests that social identification plays a pivotal role in the social comparison process of RLMX standing.

As discussed earlier, RLMX occurs in a set of differentiated LMX relationships within a workgroup that represents social status, influencing individuals' feelings of self-concept. We mentioned that high RLMX may enable employees to feel more positively as they enjoy a higher social status as compared to their coworkers in the workgroup. This, in turn, should facilitate 
their sense of social identification (focusing on shared interests and the prototypical way in the workgroup). The member is therefore likely to feel s/he is an important part of the workgroup and comes to view the group’s successes as her or his own personal successes (Ashforth \& Mael, 1989; Mael \& Ashforth, 1992). Positive self-concept enables group members to realize the importance of their work roles by contributing their concerted effort to carry out their assigned job duties in order to increase the overall group effectiveness. Findings by Randel and Jaussi (2003) suggest that employees who identify with coworkers sharing similar functional backgrounds are more likely to perform better in cross-functional workgroups. On this basis, we suggest that, when the RLMX of employees increases, the resulting sense of social identification encourages employees to integrate their self-concept as part of the workgroup, elevating their commitment to performance effectiveness and efficiency. Thus, we theorize that social identification is a proximal outcome through which RLMX is associated with more distal outcomes (i.e., job performance); and predict:

Hypothesis 3: Social identification mediates the relationship between RLMX and job performance (after controlling for individuals’ perceptions of LMX).

\section{The Moderating Role of Negative Affectivity}

A review of research has demonstrated that positive affectivity (PA) and negative affectivity (NA) are conceptually and empirically independent from each other, as distinct from opposite ends of a bipolar continuum (see Dasborough \& Ashkanasy, 2005; Judge \& Locke, 1993). Indeed, as Watson (2000) has noted, PA and NA operate through different biological and behavioral mechanisms (see also Ashkanasy \& Ashton-James, 2007; Kaplan, Bradley, Luchman, \& Haynes, 2009). This suggests that PA and NA should be conceptualized as separate constructs, examining their differential impacts on different work attitudes and behaviors (Watson, 2000). 
With respect to this, past research shows that affective-based personality of employees such as PA and NA may affect LMX relationships.

We argue that NA rather than PA is theoretically relevant and important in the context of this study for three reasons. First, NA tends to increase employees’ susceptibility or responsiveness to work stimuli such as relative LMX standing in a workgroup that generates more extreme negative reactions to such stimuli than PA (Watson, 2000). Second, NA employees are less likely to seek direct control of their RLMX than PA that may be related to why they would negatively view and define themselves in a set of differentiated LMX relationships with other coworkers in the workgroup (Watson, 2000). Third, it is also important to understand how to manage NA employees in workgroups because it can be expected that low NA employees with high RLMX may experience high levels of identification with their workgroup. Thus, focusing on NA makes sense in light of the relative LMX standing observed by different employees in workgroups. Consequently, we expect that NA should attenuate the relationship between RLMX and social identification.

Watson and Clark (1984) define NA as a dispositional tendency which reflects pervasive individual differences in negative emotionality and self-concept. Larsen and Ketelaar (1991) note further that, compared to their low NA counterparts, employees high in NA tend to be more sensitive to negative stimuli such as personal mistakes and shortcomings; and experience more negative emotions, such as anxiety, guilt, anger, frustration, sadness, distress, and worry. NA has also been shown to be associated with counter-productive behaviors (Penney \& Spector, 2005), job stress (Moyle, 1995), retaliation (Skarlicki, Folger, \& Tesluk, 1999), negative emotions (Yang \& Diefendorff, 2009), lower job satisfaction (Spector, Fox, Penney, Bruursema, Goh, \& 
Kessler, 2006), lower organizational commitment (Cropanzano, James, \& Konovsky, 1993), and lessened organizational citizenship behavior (Hui et al., 1999).

Although no research has yet been undertaken to explain why employees with different levels of NA may be more likely to make social comparisons with respect to their RLMX standing in workgroups, we propose that NA may play an important role in the relationship between RLMX and social identification. According to person-situation interactional theory (Mischel, 1968, 1977), perceptions of a situation can interact with personality characteristics to jointly explain employees’ work attitudes and behaviors. In the seminal work of person-situation interactional theory, Mischel (1968) proposed that personality characteristics determine why and when social situations are likely to predict an outcome. On this basis, we argue that low NA employees may respond more positively to the effect of high RLMX standing by experiencing higher levels of social identification as compared to high NA employees within the workgroup. Thus, the relationship between RLMX and social identification should be stronger for those who are low in NA than for those who are high in this characteristic. The logic behind this prediction is that NA is a personality characteristic that is related to the way employees feel and react to their RLMX standing. For example, Cropanzano et al. (1993) reported that employees with low NA tend to perceive their situations in a less pessimistic way than those with high NA, and are more proactive in seeking resources and help to manage any undesirable situations. Gibbons and Buunk (1999) also found that low NA employees tend to socially compare less often than high NA employees because they have higher self-esteem.

In terms of the theoretical model we propose, moreover, a low NA tendency may also have implications for employees with a higher RLMX standing. We argue in this respect that employees with low NA may experience high levels of social identification in response to high 
RLMX. This is because employees with low NA may be likely to be relatively more sensitive to the positive aspects of high RLMX, reducing their high arousal negative emotions. It is expected that high RLMX affirms positive expectations of low NA employees about their workgroup. On the other hand, we also anticipate that, compared to low NA employees, the relationship between RLMX and social identification should be weaker for high NA employees. This is supported by Levin and Stokes (1989), who noted that, "High levels of NA are associated with a type of cognitive bias through which people approach and interpret their life experiences. This affective tendency and cognitive style may influence how people experience and evaluate their jobs” (p. 753). High NA employees also tend to focus on negative cues in social situations and they are relatively emotionally unstable. As a result, positive aspects of the situation might have less impact on high NA employee’s attitudes and behaviors (Moyle, 1995).

On this basis, we argue further that employees high in NA might tend not to experience the positive aspects of their high RLMX as compared with those who have low NA. High NA employees would thus be likely to respond to their RLMX in a more negative fashion than low NA employees by being cynical and distrustful as well as by seeing themselves as targets for exploitation. Given also that high NA employees suffer from a poor self-concept (Cropanzano et al., 1993) and more often compare themselves with others (Gibbons \& Buunk, 1999), we predict they would also be less sensitive to positive feelings of calm, relaxation, or satisfaction associated with their high RLMX (Hui et al., 1999; Hochwarter \& Byrne, 2005). We therefore propose:

Hypothesis 4: Employees' NA moderates the relationship between RLMX and social identification, such that RLMX has a stronger positive impact on social identification for employees lower on NA as compared to those who are higher on NA. 


\section{Moderated Mediation}

Finally, we argue that social identification will not only mediate the relationship between RLMX and job performance, but also will mediate the interactive effect of RLMX and employees’ NA on job performance. Based on the tenets of SIT, we argue that social identification reflects the characteristics concerning the needs of emotional bonding and feelings of affiliation. Although different levels of employees’ NA is related to how they respond to the effect of high or low RLMX in the workgroup (which in turn may be associated with their social identification), the levels of social identification are still essential to be related to employees’ job performance. Following on the preceding discussion regarding Hypotheses 2, 3 and 4, we contend that, when employees have low levels of NA, the effect of RLMX on social identification and ultimately on job performance will be stronger. In contrast, when employees have high levels of NA, the effect of their RLMX on social identification and ultimately on job performance will be weaker. Hence, we propose as our final hypothesis:

Hypothesis 5: Social identification mediates the interactive effect of RLMX and employees' negative affectivity on job performance.

\section{Methods}

\section{Participants and Procedure}

Participants were employees and their immediate managers working in the local branches of two large Australian banks. All the branches consisted of five to eight employees, and each employee was required to report to their branch manager on a daily basis. We included only branch managers who had been in their positions for more than 12 months; and employees who had been in their branch for more than 6 months. This was to ensure that employees were 
sufficiently acquainted with their coworkers and managers in order to have developed interpersonal relationships with them.

Questionnaires were sent through the internal mail system of each bank. Different questionnaires were used to collect data from managers and employees. Manager questionnaires were distributed to 75 branch managers, and each manager was asked to provide general performance ratings for her or his immediate subordinates. Employee questionnaires were sent to 555 employees, and each subordinate was asked to provide responses to items pertaining to her or his perception of LMX with her or his manager, social identification and negative affectivity. The employee questionnaires were matched to the responses of their managers using a coding provided by the human resources managers of the banks.

Of the 75 manager questionnaires and 555 employee questionnaires we distributed, 52 manager questionnaires (69\% response rate) and 336 employee questionnaires (61\% response rate) were returned. After excluding incomplete questionnaires and those failing to match with a manager within each branch, the sample was comprised of 252 manager-employee dyads in 42 bank branches. Each branch manager rated the job performance of 4 to 8 subordinates $(\mathrm{M}=6)$. Eighty-four percent of the managers were women, 69\% were aged 45 years or below. The managers had been employed in the organization between 1 to 28 years ( $\mathrm{M}=14$ years) and their average experience working in their present position was 3.8 years. Among the employees in the sample, $89 \%$ were women and $81 \%$ were aged 45 years or below. They had been employed in the organization for 2.8 years on average.

\section{Measures}

Leader-member exchange. We used the LMX-7 scale (Graen \& Uhl-Bien, 1995) to measure the relationship quality between branch managers and their employees. An example item 
is: “To what extent does your manager understand your work problems and needs;” alpha reliability $=.94$.

Relative leader-member exchange. We followed the operationalization outlined by Henderson et al. (2008), Vidyarthi and Liden (2009) and Hu and Liden (2009) to assess RLMX. Thus, we subtracted the mean LMX score within a group from each group member's composite LMX score (also see Kozlowski \& Klein, 2000). Note in particular that, in contrast to Vidyarthi et al. (2010), we elected not to use polynomial regression analysis (Edwards \& Parry, 1993). This is because Edwards' (1995) original critique of difference scores dealt with the problems associated with difference scores between two perceptual variables. This is not, however, an issue when simply subtracting the mean from each individual LMX score on a single variable, which is what is done to calculate RLMX. Inspection of Vidyarthi and colleagues’ results (see their Figure 2) confirms that the polynomial results they obtained are planar (which would not be the case if difference scores were a problem).

Social identification. This was measured using the 3-item identification scale developed by Mael and Ashforth (1989), and subsequently modified by Randel and Jaussi (2003). This scale captures the social identity theory principle that "social identification is perceived as personally experiencing the success and failures of a particular group or subgroup” (Mael \& Ashforth, 1989, p. 21). Respondents were asked to indicate their perceptions of social identification with their group in general. An example item is: "When other members in my team are recognized for their accomplishments, I feel like I have accomplished something too;” alpha reliability = .76.

Negative affectivity. The 10-item negative affectivity scale of the Positive and Negative Affect Schedule (PANAS; Watson, Clark, \& Tellegen, 1988) was used to assess employees’ negative affectivity. The negative affectivity scale of the PANAS consists of 10 adjectives that 
describe negative emotions (e.g., angry, distressed, upset). Respondents were asked to indicate the extent to which they generally feel each of the emotional adjectives; alpha reliability $=.89$.

Job performance. Three items from a task performance instrument by Heilman, Block, and Lucas (1992) were used to assess employees’ job performance. Branch managers were asked to provide a performance rating for each employee within their branch. An example item is: “This employee gets his or her work done very effectively”, alpha reliability = .94.

Given the 252 subordinates were nested in 42 workgroups, and supervisors were asked to provide performance ratings for multiple subordinates in each workgroup, we conducted ANOVA and intra-class correlation (ICC) tests to identify whether there was systematic betweengroup variance in job performance (Bliese, 2000). ANOVA result $(F=1.270, n s)$ and ICC (1) and ICC (2) values for job performance of 04 and .21 suggests that there was no substantial between-group variation in individual job performance ratings. These results provide support for the subsequent analyses to be conducted at the individual level.

Controls. Sex and age of subordinates were included as control variables. These controls were necessary because these variables have been shown to influence the outcome variables in previous research (e.g., Van Der Vergt, Van De Vliert, \& Oosterhof, 2003). In addition, we controlled for employees' length of work experience with group members and their interaction frequency with other group members because these variables may potentially explain job performance (Rentsch \& Klimoski, 2002; Pelled, Eisenhardt, \& Xin, 1999). Coding schemata for the categorical control variables are shown in Table 1. 


\section{Results}

\section{Confirmatory Factor Analyses}

We conducted a series of confirmatory factor analyses (CFA) using AMOS 5 to examine the distinctiveness of our study variables based on chi-square statistics and fit indices of RMSEA, IFI and CFI (Anderson \& Gerbing, 1988; Joreskog, 1993). Results showed that the hypothesized 4-factor model of LMX, social identification, negative affectivity, and manager-rated job performance, $\chi 2=587.71, d f=224 ; R M S E A=.08 ; C F I=.92$ and $I F I=.92$, yielded a better fit to the data than any other models including a 1-factor model (i.e., combining all four study variables), $\chi 2=2132.30 . d f=230 ; \mathrm{RMSEA}=.018 ; \mathrm{CFI}=.53$ and TLI $=.53$. These CFA results also provide support for the distinctiveness of the four study variables for subsequent analyses.

\section{Descriptive Statistics}

Table 1 presents descriptive statistics, reliabilities and inter-correlations for all variables. Consistent with our predictions, RLMX was positively related to social identification and job performance. Furthermore, social identification was positively related to job performance.

Insert Table 1 here

\section{Hypothesis Tests}

We conducted hierarchical regression analyses by entering control variables, LMX, and the study variables into different steps of the equation. Table 2 reports the regression results relating to Hypotheses 1 to 4 . To test Hypothesis 1, we examined the positive relationship between RLMX and social identification. Results in Table 2 show that RLMX was positively related to 
social identification $(\beta=.20, \mathrm{p}<.01)$ after controlling for individuals’ perceptions of LMX. Hence, Hypothesis 1 received support.

Insert Table 2 here

Next, we tested Hypotheses 2 and 3, where we expected to find a main effect of social identification on job performance; and also that social identification would mediate the relationship between RLMX and job performance. Based on Edwards and Lambert (2007), we used bootstrap confidence intervals to test our mediation hypotheses because they are biascorrected. Results showed that a significant indirect effect between RLMX and job performance was also observed in the predicted direction $(\beta=.13, \mathrm{p}<.01)$. A one-tailed Sobel test also supported the significance of this indirect effect $(z=3.88, p<.01)$, as did bootstrap results showing that a 95\% bias corrected confidence interval $(.07<->.23)$ did not contain zero. Hence, Hypotheses 2 and 3 received support, as social identification not only had a direct impact on job performance, but also mediated the relationship between RLMX and job performance.

In Hypothesis 4, we predicted that NA would moderate the relationship between RLMX and social identification. Step 3 of Table 2 reveals that the interaction term of RLMX and NA had a significant negative impact on social identification, after controlling for perceptions of LMX, and the explained variance of the interaction term was significant $\left(\triangle R^{2}=.20, p<.01\right)$. As suggested by Aiken and West (1991), we illustrated the pattern of the interaction effect using one standard deviation above and below the mean of negative affectivity to represent high and low NA. Figure 2 reveals that employees with lower levels of NA experienced higher levels of social identification when their RLMX in the workgroup was higher than other coworkers’ LMX relationships (slope: $\beta=.63, t=1.78, p<.01$ ). In contrast, employees with higher levels of NA 
experienced lower levels of social identification even though their RLMX in the workgroup was higher than other coworkers' LMX relationships (slope: $\beta=.29, t=.82, p<.05$ ). The regression and simple effects results provide support for Hypothesis 4, suggesting that RLMX has a stronger impact on social identification for employees lower on NA as compared to those who are higher on NA.

Finally, we examined Hypothesis 5, where we anticipated that social identification would mediate the interactive effect of RLMX and employees' NA on job performance. Since this hypothesis involved testing moderating and mediating relationships simultaneously, we continued to adopt the moderated-mediation approach outlined by Edwards and Lambert (2007). As the approach outlines, there are possibilities that the moderation can influence different stages of a three-variable mediation chain $(\mathrm{X} \rightarrow \mathrm{M} \rightarrow \mathrm{Y}$ ). Specifically, the moderation effect can occur at (1) the first stage $(\mathrm{X} \rightarrow \mathrm{M})$; (2) the second stage $(\mathrm{M} \rightarrow \mathrm{Y})$; (3) both the first and second stages - $(\mathrm{X} \rightarrow \mathrm{M}$ and $\mathrm{M} \rightarrow \mathrm{Y})$, or (4) in all stages, which includes the first and second stages and the additional relationship between independent variable and outcome $(\mathrm{X} \rightarrow \mathrm{M}, \mathrm{M} \rightarrow \mathrm{Y}$, and $\mathrm{X} \rightarrow \mathrm{Y}$ ). We also used the hierarchical regression equations developed by Edwards and Lambert (2007) to obtain relevant coefficients that calculate the first stage (direct effect), the second stage (indirect effect), and all stages (total effects). The significance of each of these effects can be assessed at different degrees of the moderator (one standard deviation above and below its mean). Hence, the mediation effect at different stages can be significantly stronger or weaker at a high level (above the mean), a low level (below the mean) or both levels (both above and below the mean of the moderator).

To test Hypothesis 5, we examined the first stage of moderation (i.e., NA moderates the link between RLMX and social identification) in the RLMX $\rightarrow$ social identification $\rightarrow$ outcome 
chain. We followed Cohen, Cohen, West, and Aiken’s (2003) suggestion of using mean-centered variables to create the interactive term between RLMX and NA in order to reduce the possible effect of multicollinearity for hierarchical regression analyses. Following Edwards and Lambert (2007), we separated the total effect of RLMX on job performance into direct and indirect effects at different levels of NA. The results of the direct and indirect effects at high and low levels of NA are presented in Table 3.

Insert Table 3 here

As can be seen in Table 3, at low levels of NA (one standard deviation below the mean), RLMX had a positive effect on social identification and the path from social identification to job performance was significant. Furthermore, the indirect effect of RLMX on job performance was also significant. The bootstrap result revealed that a 95\% bias corrected confidence interval $(.06<->$.84) did not contain zero. At high levels of NA (one standard deviation above the mean), RLMX had a positive effect on social identification and the path of social identification to job performance was significant. Moreover, the indirect effect of RLMX on job performance was also significant. The bootstrap results also indicated that a 95\% bias corrected confidence interval $(.04<->$.51) did not contain zero. These results show that social identification mediated the link between RLMX and job performance at both high and low levels of NA.

In sum, the results provide support for Hypothesis 5, the first stage of moderation on the mediation-chain relationship between RLMX, social identification and job performance. As can be seen in Table 3 , low NA employees $(B=.63, p<.01)$ responded more positively to the effect 
of high RLMX in their workgroup by experiencing higher levels of social identification than employees with higher NA $(B=.29, p<.01)^{1}$

\section{Discussion}

In this study, we examined the effect of employees' relative standing of differentiated LMX relationships between leaders and workgroup members (Henderson et al., 2008; Hooper \& Martin, 2008; Liden \& Antonakis, 2009; Vidyarthi et al., 2010). Specifically, we proposed a moderated-mediation model to examine the effect of relative LMX standing and the underlying processes through which it is associated with job performance. Our results support the hypothesized relationships in the model. Our key findings are fourfold. First, we found that RLMX was positively associated with social identification after controlling for individuals’ perceptions of LMX relationships. Second, we found that social identification was related to job performance, and also that social identification mediated the link between RLMX and job performance. Third, our moderation hypothesis received support in that employees’ NA attenuated the relationship between RLMX and social identification. Fourth, social identification mediated the interactive effect of RLMX and employees' NA on job performance, such that the mediated effect was stronger when employees had lower levels of NA.

\section{Implications for Theory and Research}

The present findings pave the way for future studies that might extend our current understanding of RLMX and its place in the LMX literature in several ways.

\footnotetext{
${ }^{1}$ Although we did not follow the recent LMX research (e.g., Henderson et al., 2008; Vidyarthi et al., 2010) to include group-level LMX differentiation as a control variable in our study, a series of additional HLM analyses was conducted to examine the potential effect of LMX differentiation. Results showed that LMX differentiation at the group-level did not yield any significant impact that could confound the moderating effect of NA on the relationship between RLMX and social identification, and the mediating effect of social identification on the relationship between RLMX and job performance in this study.
} 
First, we adopted SCT to underscore the importance of the actual degree to which an individual's LMX differs from the average leader-subordinate LMX in the workgroup (Vidyarthi et al., 2010). Our findings suggest that RLMX has a positive relationship with social identification, supporting the notion that RLMX is related to how employees perceive and envision themselves in the workgroup. As we mentioned in our hypothesis development, high RLMX is associated with a positive self-concept for employees in workgroups. This positive selfconcept may influence how employees promote collective identity, emphasize common experience, and focus on shared interests. The implication of this is that the more group members feel validated and accepted by virtue of high RLMX standings, the more they may feel motivated towards identifying with others (cf. Henderson et al., 2008). We are unaware of any previously published study that investigated the relationship between RLMX and social identification or other similar constructs (see Henderson et al., 2008; Hu \& Liden, 2009; Liden \& Antonakis, 2009; Vidyarthi et al., 2010).

Second, our findings shed new light on the psychological process through which RLMX is related to work behavior (Henderson et al., 2008; Hu \& Liden, 2009). Ashforth and Mael (1989) argued that employees with high levels of social identification are likely to be motivated to define themselves based on group values, and therefore tend to perceive group successes and failures as their own. In the present study, we examined social identification as a mechanism linking RLMX and job performance. We found that social identification mediated the relationship between RLMX and job performance. This suggests that high relative LMX standing in the workgroup can be interpreted in terms of employees' identity and as accommodating to the needs of selfenhancement. Social identification can therefore be seen as a form of social currency whereby employees might increase their commitment to performance efficiency and effectiveness. 
Third, we extend the research of Henderson et al. (2008) and Vidyarthi et al. (2010), to show that an individual difference - negativity affectivity - improves our understanding as to when and why some employees feel and respond to high and low RLMX differentially. In this respect, we found that employees’ NA attenuated the relationship between RLMX and social identification. In particular, low NA employees’ social identification was enhanced by an RLMX standing that is higher rather than lower than other coworkers' LMX relationships. On the other hand, high NA employees were relatively less sensitive to high RLMX effects and they also experienced lower levels of social identification than low NA counterparts. These findings also provide evidence in support of a person-situation interactional perspective as a means to explain why employees with different personality characteristics respond differentially to LMX relationships.

We further demonstrate that the mediation-chain relationship is more complicated than was previously understood, in that the relationship appears to vary with employee NA. By utilizing Edwards and Lambert's (2007) moderated-mediation approach, we found that the mediating effect of social identification on the link between RLMX and job performance at different stages can be significantly stronger or weaker, depending on member NA. In particular, we found that the mediation effect of social identification in the relationship between the variables was stronger for employees with lower NA.

\section{Implications for Practice}

The findings of our study also have practical implications. First, it appears that employees may be aware of their relative LMX standing as compared with other coworkers' LMX relationships in the workgroup. This is because the RLMX standing represents an actual position of an employee in a set of differentiated LMX relationships in the workgroup (Henderson et al., 
2008; Hu \& Liden, 2009; Vidyarthi et al., 2010). Thus, managers may need to become more aware of how employees differentiate between high and low LMX coworkers. As suggested by Henderson et al. (2008) and Hooper and Martin (2008), LMX differentiation (the degree of variability in the quality of LMX relationships formed within workgroups) plays a role in the social comparison process of LMX relationships that may be associated with the saliency of the RLMX differences (cf. Henderson et al., 2008; Hu \& Liden, 2009).

Another practical implication is related to the moderating effect of employees' negative affectivity. Our results inform us that low NA employees react more positively to their high RLMX standing and they may experience higher levels of social identification than do high NA employees. Given NA is a relatively stable personality trait, our findings suggest that low NA employees with high RLMX may be less likely to experience negative emotions of distress, anger, jealousy, and frustration and provoke these emotions in others. The resulting emotional contagious effect might be associated with other coworkers' levels of social identification and job performance (cf. Dasborough, Ashkanasy, Tee, \& Tse, 2009; Tse \& Ashkanasy, 2008). Thus, organizations might deploy more resources to the selection and recruitment process for low NA employees.

\section{Limitations and Future Research Directions}

The present study was subject to five limitations.

First, the use of a cross-sectional design makes it difficult to determine the direction of causality among the study variables, and thus cause-effect relationships should not be inferred from our findings. Although our results are consistent with the hypothesized relationships in the model, it is intuitively possible to develop alternative explanations for the relationships in the 
model. In this instance, field experiments and longitudinal research designs might be needed to eliminate possible alternative explanations for our findings.

A second limitation concerns the potential for common method variance conflating relationships between the variables because social identification and negative affectivity were measured from the same source (Podsakoff, MacKenzie, Lee, \& Podsakoff, 2003). We adopted three strategies to minimize this effect, following recommendations by Posdakoff et al. (2003). First, our main variable of interest, RLMX was operationalized by subtracting the mean LMX score within a workgroup from each workgroup member's composite LMX score (Henderson et al., 2008; Vidyarthi et al., 2010). It therefore is unlikely to engender common method variance. Second, we collected data about job performance from branch managers. Third, our model involved testing a moderated-mediation relationship, which is actually less likely to be detected when relationships are artificially inflated (Edwards \& Lambert, 2007). Thus, we are confident that common method variance did not unduly influence the hypothesized relationships in this study. Nevertheless, future research should attempt to replicate the current findings by collecting data at different points in time to increase confidence in the findings.

A third limitation relates to the potential non-respondent bias influencing the validity of our findings because the final sample of 252 manager-employee dyads out of 555 sampled dyads was below 50\% after excluding incomplete questionnaires and those failing to match with a manager within each branch. Because of ethical concerns and personal privacy, the HR managers of the banks declined to provide us with personal particulars of the managers and employees who chose not to participate in our research. We understand that there is a possibility that there might have been systematic differences in the subjects who refused to participate versus those who did 
participate in our research. We however were unable to include all non-respondents for a nonresponse bias test to examine its potential impact.

A fourth limitation is that we were unable to directly compare our results with those reported in Vidyarthi et al.'s (2010) study because their measure of perceived RLMX or LMXSC was not included. By incorporating LMXSC, the findings of our study would have been informative to compare the relative value of LMXSC and social identification as a mediator in the relationships tested in our model. Future research should consider furthering our understanding of other relevant variables that would potentially mediate the relationships between RLMX and work attitudes and behaviors.

A fifth potential problem associated with the sample may be seen to be a possible lack of generalizability. The sample consisted of mostly female employees and their branch managers from two major banking organizations. Our findings may have been different if there had been more male employees in the sample, although females seem to dominate the workforce in the banking industry in many countries. For example, $66.5 \%$ of the workforce is female in the banking and related sectors in the United States (Bureau of Labor Statistics, 2008), whereas 60\% of the workforce is female in the same sectors in Australia (Australian Bankers’ Association, 2009). Thus, our results may still be generalizable to other industries where females are a dominant workforce.

Finally, although not a limitation per se, our study was focused on employee task behavior. Previous research (e.g., see Chiaburu \& Harrison, 2008; Vidyarthi et al., 2010) has examined the effects of team-member relations and RLMX on OCBs, so future researchers may wish to examine our model in terms of contextual performance. 
In conclusion, and despite the limitations outlined above, we believe that our study contributes to the literature on LMX in that it is the first to test a moderated-mediation model of processes whereby an employee's LMX relative to other coworkers’ LMX within a workgroup is related to her or his work behaviors. Our findings provide support for the model we hypothesized, thus confirming that RLMX influences job performance through social identification. We also showed that members’ negative affectivity moderates the link between RLMX and social identification. Moreover, we found that social identification mediates the interactive effect of RLMX and NA on the outcome variable.

\section{References}

Aiken, L. S., \& West, S. G. (1991). Multiple regression: Testing and interpreting interactions. Newbury Park, CA: Sage.

Anderson, J. C., \& Gerbing, D.W. (1988). Structural equation modeling in practice: A review and recommended two-step approach. Psychological Bulletin, 103, 411-423.

Ashforth, B. E., \& Mael, F. (1989). Social identity theory and the organization. Academy of Management Review, 14, 20-39.

Ashkanasy, N. M., \& Ashton-James, C. E. (2007). Positive emotion in organizations: A multi-level framework. In C. L. Cooper \& D. Nelson (Eds.), Positive organizational behavior (pp. 57-73). Chichester, UK: John Wiley and Sons.

Australian Bankers’ Association. (2009). Banking facts and figures - employment and wages. Retrieved from http://www.bankers.asn.au/Employment-and-wages/default.aspx Baldwin, M. W. (1992). Relational schemas and the processing of social information. Psychological Bulletin, 112, 461-484. 
Bauer, T. N., \& Green, S. G. (1996). Development of leader-member exchange: A longitudinal test. Academy of Management Journal, 39, 1538-1567.

Bliese, P. (2000). Within-group agreement, non-independence, and reliability. In K. Klein and S. Kozlowski (Eds.), Multilevel theory, research, and methods in organizations (pp. 349-381). San Francisco, CA: Jossey-Bass.

Brewer, M. B., \& Gardner, W. (1986). Who is this “we”? Levels of collective identity and selfrepresentations. Journal of Personality and Social Psychology, 71, 83-93.

Bureau of Labor Statistics. (2008). Employed persons by detailed industry and sex, 2007 annual averages. Retrieved from http://www.bls.gov/cps/wlf-table14-2008.pdf

Buunk, A. P., \& Gibbons, F. X. (2007). Social comparison: The end of a theory and the emergence of a field. Organizational Behavior and Human Decision Processes, 102, 3-21.

Chiaburu, D. S., \& Harrison, D. A. (2008). Do coworkers make the place? Conceptual synthesis and meta-analysis of lateral social influences on perceptions, attitudes and OCBs, and performance. Journal of Applied Psychology, 93, 1082-1103.

Cohen, J., Cohen, P., West, S. G., \& Aiken, L. S. (2003). Applied multiple regression/correlation analysis for the behavioral sciences ( $3^{\text {rd }}$ ed.). Hillsdale, NJ: Lawrence Erlbaum.

Cropanzano, R., James, K., \& Konovsky, M. A. (1993). Dispositional affectivity as a predictor of work attitudes and job performance. Journal of Organizational Behavior, 14, 595-606.

Dansereau, F., Graen, G. B., \& Haga, W. J. (1975). A vertical dyad linkage approach to leadership within formal organizations. Organizational Behavior and Human Performance, 13, 46-78.

Dasborough, M. T., \& Ashkanasy, N. M. (2005). Follower emotional reactions to authentic and inauthentic leadership influence. In W. L. Gardner, B. J. Avolio, \& F. O. Walumbwa (Eds.). Monographs in leadership and management (vol. 3, pp. 281-300). Oxford, UK: Elsevier/JAI 
Press.

Dasborough, M. T., Ashkanasy, N. M., Tee, E. E. J., \& Tse, H. H. M. (2009). What goes around comes around: How meso-level negative emotional contagion can ultimately determine organizational attitudes toward leaders. The Leadership Quarterly, 20, 571-585.

Dienesch, R. M., \& Liden, R. C. (1986). Leader-member exchange model of leadership: A critique and further development. Academy of Management Review, 11, 618-634.

Duchon, D., Green, S. G., \& Taber, T. D. (1986). Vertical dyad linkage: A longitudinal assessment of antecedents, measures, and consequences. Journal of Applied Psychology, 71, 56 - 60.

Edwards, J. R. (1995). Alternatives to difference scores as dependent variables in the study of congruence in organizational research. Organizational Behavior and Human Decision Processes, 64, 307-324.

Edwards, J. R., \& Lambert, L. S. (2007). Methods for integrating moderation and mediation: A general analytical framework using moderated path analysis. Psychological Methods, 12, 1-22.

Edwards, J. R., \& Parry, M. E. (1993). On the use of polynomial regression equations as an alternative to difference scores in organizational research. Academy of Management Journal, 36, 1577-1613.

Festinger, L. (1954). A theory of social comparison processes. Human Relations, 7, 117-140. Gardner, W. L., Gabriel, S., \& Hochschild, L. (2002). When you and I are "we," you are not threatening: The role of self-expansion in social comparison. Journal of Personality and Social Psychology, 82, 239-251.

Gerstner, C. R., \& Day, D. V. (1997). Meta-analytic review of leader-member exchange theory: Correlates and construct issues. Journal of Applied Psychology, 82, 827-844. 
Gibbons, F. X., \& Buunk, B. P. (1999). Individual differences in social comparison: Development of a scale of social comparison orientation. Journal of Personality and Social Psychology, 76, 129-142.

Graen, G., \& Cashman, J. (1975). A role-making model of leadership in formal organizations: A development approach. In J. G. Hunt \& L. L. Lawson (Eds), Leadership frontiers (pp. 143165). Kent, OH: Kent State University Press.

Graen, G. B., Liden, R. C., \& Hoel, W. (1982). Role of leadership in the employee withdrawal process. Journal of Applied Psychology, 67, 682-872.

Graen, G. B., \& Uhl-Bien, M. (1995). Relationship-based approach to leadership: Development of leader-member exchange (LMX) theory of leadership over 25 years: Applying a multi-level multi-domain perspective. The Leadership Quarterly, 6, 219-247.

Greenberg, J., Ashton-James, C. E., \& Ashkanasy, N. M. (2007). Social comparison processes in organizations. Organizational Behavior and Human Decision Processes, 102, 22-41.

Heilman, M. E., Block, C. J., \& Lucas, J. A. (1992). Presumed incompetent? Stigmatization and affirmative action efforts. Journal of Applied Psychology, 77, 536-544.

Henderson, D. J., Liden, R. C., Glibkowski, B. G., \& Chaudhry, A. (2009). Within-group LMX differentiation: A multilevel review and examination of its construct definition, antecedents and outcomes. The Leadership Quarterly, 4, 517-534.

Henderson, D. J., Wayne, S. J., Shore, L. M., Bommer, W. H., \& Tetrick, L. E. (2008). Leadermember exchange: Differentiation, and psychological contract fulfillment: A multilevel examination. Journal of Applied Psychology, 93, 1208-1219. 
Hochwarter, W. A., \& Byrne, Z. S. (2005). Leader member exchange and job tension: Linear and non-linear effects across levels of affective disposition. Journal of Business and Psychology, 20, 171-190.

Hogg, M. A., \& Abrams, D. (1988). Social identifications: A social psychology of intergroup relations and group processes. London: Routledge.

Hogg, M. A., \& Terry, D. J. (2000). Social identity and self-categorization processes in organizational contexts. Academy of Management Review, 25, 121-140.

Hooper, D. T., \& Martin, R. (2008). Beyond personal leader-member exchange (LMX) quality: The effects of perceived LMX variability on employee reactions. The Leadership Quarterly, 19, 20-30.

Hu, J., \& Liden, R. C. (2009). Relative leader-member and individual performance and job satisfaction: The role of group supportive behavior, task interdependence and psychological empowerment. Paper presented at the annual meeting of the Academy of Management, Chicago, Illinois, USA.

Hui, C., Law, K. S., \& Chen, Z. X. (1999). A structural equation model of the effects of negative affectivity, leader-member exchange and perceived job mobility on in-role and extra-role performance: A Chinese case. Organizational Behavior and Human Decision Processes, 77, 321.

Joreskog, K. G. (1993). Testing structural equation models. In K. A. Bollen \& J. S. Long (Eds.), Testing structural equation models (pp. 294-316). Newbury, CA: Sage

Judge, T. A., \& Locke, E. A. (1993). Effect of dysfunctional thought processes on subjective wellbeing and job satisfaction. Journal of Applied Psychology, 78, 475-490. 
Kamdar, D., \& Van Dyne, L. (2007). The joint effects of personality and workplace social exchange relationships in predicting task performance and citizenship performance. Journal of Applied Psychology, 92, 1286-1298.

Kaplan, S., Bradley, J. C., Luchman, J. N., \& Haynes, D. (2009). On the role of positive and negative affectivity in job performance: A meta-analytic investigation. Journal of Applied Psychology, 94, 162-176.

Kozlowski, S. W. J., \& Klein, K. J. (2000). A multi-level approach to theory and research in organizations: Contextual, temporal and emergent processes. In K. J. Klein \& S. W. J. Kozlowski (Eds.), Multi-level theory, research, methods in organizations (pp. 3-90). San Francisco: Jossey-Bass.

Kramer, M. W. (1995). A longitudinal study of supervisor-subordinate communication during job transfers. Human Communication Research, 22, 39-64.

Larsen, R. J., \& Ketelaar, T. (1991). Personality and susceptibility to positive and negative emotional states. Journal of Personality and Social Psychology, 61, 132-140.

Levin, I., \& Stokes, J. (1989). A dispositional approach to job satisfaction: The role of negative affectivity. Journal of Applied Psychology, 74, 752-758.

Liden, R. C., \& Antonakis, J. (2009). Considering context in psychological leadership research. Human Relations, 61, 1587-1605.

Mael, F., \& Ashforth, B. E. (1992). Alumni and their alma mater: A partial test of the reformulated model of organizational identification. Journal of Organizational Behavior, 13, 103-123.

Mischel, W. (1968). Personality and assessment. New York: Wiley. 
Mischel,W. (1977). The interaction of person and situation. In D. Magnusson, \& N. S. Endler (Eds.), Personality at the crossroad: Current issues in international psychology (pp. 333-352). Hillsdale, NJ: Lawrence Erlbaum.

Moyle, P. (1995). The role of negative affectivity in the stress process: Tests of alternative models. Journal of Organizational Behavior, 16, 647-668.

Pelled, L. H., Eisenhardt, K. M., \& Xin, K. R. (1999). Exploring the black box: An analysis of work group diversity, conflict, and performance. Administrative Science Quarterly, 44, 1-28.

Penney, L. M., \& Spector, P. E. (2005). Job stress, incivility, and counterproductive workplace behavior (CWB): The moderating role of negative affectivity. Journal of Organizational Behavior, 26, 777-796.

Podsakoff, P. M., MacKenzie, S. B., Lee, J. Y., \& Podsakoff, N. P. (2003). Common method biases in behavioral research: A critical review of the literature and recommended remedies. Journal of Applied Psychology, 88, 879-903.

Randel, A. E., \& Jaussi, K. S. (2003). Functional background identity, diversity and individual performance in cross-functional teams. Academy of Management Journal, 46, 763-774.

Rentsch, J. R., \& Klimoski, R .J. (2002). Why do "great minds” think alike? Antecedents of team member schema agreement. Journal of Organizational Behavior, 22, 107-120.

Schyns, B., \& Day, D. (2010). Critique and review of leader-member exchange theory: Issues of agreement, consensus, and excellence. European Journal of Work and Organizational Psychology, 19, 1-29.

Shah, J. (2003). Automatic for the people: How representations of significant others implicitly affect goal pursuit. Journal of Personality and Social Psychology, 84, 661-681. 
Sherony, K. M., \& Green, S. G. (2002). Coworker exchange: Relationships between coworkers, leader-member exchange, and work attitudes. Journal of Applied Psychology, 87, 542-548.

Sias, P. M., \& Jablin, F. M. (1995). Differential supervisor-subordinate relations, perceptions of fairness and coworker communication. Human Communication Research, 22, 5-38.

Skarlicki, D. P., Folger, R., \& Tesluk, P. (1999). Personality as a moderator between fairness and retaliation. Academy of Management Journal, 42, 100-108.

Sparrowe, R. T., \& Liden, R. C. (1997). Processes and structure in leader-member exchange. Academy of Management Review, 22(2), 522-552.

Sparrowe, R. T., \& Liden, R. C. (2005). Two routes to influence: Integrating leader-member exchange and network perspectives. Administrative Science Quarterly, 50, 505-535.

Spector, P. E., Fox, S., Penney, L. M., Bruursema, K., Goh, A., \& Kessler, S. (2006). The dimensionality of counterproductivity: Are all counterproductive behaviors created equal? Journal of Vocational Behavior, 68, 446-460.

Stamper, C. L., \& Masterson, S. S. (2002). Insider or outsider? How employee perceptions of insider status affect their work behavior. Journal of Organizational Behavior, 23, 875-894.

Stapel, D. A., \& Koomen, W. (2005). Competition, cooperation, and the effects of others on me. Journal of Personality and Social Psychology, 88, 1029-1038.

Tajfel, H. (1972). Social categorization. English translation of 'La categorization sociale’. In S. Mosocovici (Ed.), Introduction La Psychologie Sociale (pp. 272-302). Paris: Larousse.

Tajfel, H. (1978). The achievement of group differentiation. In H. Tajfel (Ed.), Differentiation between social groups: Studies in social psychology of inter-group relations (pp. 77-98). London: Academic Press. 
Tajfel, H., \& Turner, J. C. (1986). The social identity theory of inter-group behavior. In S. Worchel \& L. W. Austin (Eds.), Psychology of intergroup relations (pp. 1-10). Chicago: Nelson-Hall.

Tse, H. M. \& Ashkanasy, N. M. (2008). The role of affect in vertical and lateral exchange work relationships in teams. In N. M. Ashkanasy \& C. L. Cooper (Eds.), Research companion to emotions in organizations (pp. 499-512). Cheltenham, UK: Edwin Elgar.

Tse, H. M. Dasborough, M., \& Ashkanasy, N. M. (2008). A multilevel analysis of team climate and interpersonal exchange relationships at work. Leadership Quarterly, 19, 195-211.

Turner, J. C., Hogg, M. A., Oakes, P. J., Reicher, S. D., \& Wetherell, M. C. (1987). Rediscovering the social group: A self-categorization theory. New York: Basil Blackwell.

Van Der Vegt, G. S., Van De Vliert, E., \& Oosterhof, A. (2003). Informational dissimilarity and organizational citizenship behavior. The role of intrateam interdependence and team identification. Academy of Management Journal, 46, 715-727.

Van Knippenberg, D. (2000). Work motivation and performance: A social identity perspective. Applied Psychology: An International Review, 49, 357-371.

Vidyarthi, P. R., Liden, R. C., Anand, S., Erdogan, B., \& Ghosh, S. (2010). Where do I stand? Examining the effects of leader-member exchange social comparison on employee work behaviors. Journal of Applied Psychology, 95, 849-861.

Watson, D. (2000). Mood and temperament. New York: Guilford Press.

Watson, D., \& Clark, L. A. (1984). Negative affectivity: The disposition to experience aversive negative states. Psychological Bulletin, 96, 465-490.

Watson, D., Clark, L. A., \& Tellegen, A. (1988). Development and validation of brief measures of positive and negative affect: The PANAS scale. Journal of Personality and Social Psychology, 54, 1063-1070. 
Williams, L. J., \& Anderson, S. E. (1991). Job satisfaction and organizational commitment as predictors of organizational citizenship and in-role behaviors, Journal of Management, 17, 601-617.

Yang, J., \& Diefendorff, J. (2009). The relations of daily counterproductive workplace behavior with emotions, situational antecedents and personality moderators: A diary study in Hong Kong. Personnel Psychology, 62, 259-295. 